\title{
FIRES IN WOOD INDUSTRY
}

\author{
Nenad Papić \\ Forensic Science Centre „Ivan Vučetič“, Ilica 335, 10000 Zagreb - Croatia
}

\begin{abstract}
In recent years, there were a few fires of equipments in wood industry in Croatia, after which in fire scene investigation and determination of fire cause working, as a part of team, experts from Forensic Science Centre „Ivan Vučetič“ (FSC „Ivan Vučetić“). One of this fires in wood industry was the fire in the "Wood Industry Bohor". In the paper is described the manner of work of the expert witnesses when there determined the cause of fire in industrial equipments. There are given methods of determining the cause of fire and point at characteristic defects which may cause a fire.
\end{abstract}

Keywords: fire, wood industry, expert witnesses, cause of fire

\section{INTRODUCTION}

Investigation of cause of fire in industrial equipments has been conducted as a review of fire scene and examination of electrical installation and electrical appliances. Working on the fire scene is a team work, which means that at the scene there are an expert team of chemical, electrical and mechanical engineer from Forensic Science Centre „Ivan Vučetić“. Each of experts review fire scene and search for characteristics traces on all parts of the building, on equipment and electrical installation, and they together locate the centre of the fire, the place where the fire start.

Before starting the investigation of fire scene, experts are looking for information about place and time of starting the fire, statements of eyewitnesses and fire fighters, statements of the owner and employments, video tapes or photos of fire, and looking for information of fire protection and video surveillance. Also experts are reviewing the technical documentation and schemes of electrical installation.

Before entering the fire scene and starting investigation, it is necessary to determine whether the power supply is turned off (disconnected) for the safety of the people who move and perform the views of the burned object. Also it is necessary to check gas supply.

Visual inspection of the fire scene should be determined thermal damages on the outside and inside the building, and all identified traces photographed or videotaped. Detailed examination of the interior of the object should be determined the place of the largest thermal destructions (location of centre of fire). Inspection and testing of electrical installations, electrical devices and parts of equipment on the place of largest thermal damages, should determined the thermal damages of cables, in distribution boxes with fuses and on parts of equipment and to find the faults that are related to the possible cause of fire. All identified traces should be photographed or videotaped and all relevant traces should be exempted after recording (traces of characteristic faults which may cause a fire).

Crime Scene Unit team take photographs of the fire scene and take a detailed record of the examination of the fire scene. After determining the fault by the experts, the location of the fault is photographed and at the request of the expert shall be exempt found traces (fire debris, parts of electrical installations with traces of failure or other). Exempt material from the scene is delivered to the next expertise in Forensic Science Centre „Ivan Vučetić“.

The results of the examination of the fire scene and the opinion of the cause of the fire are recorded by writing record of the expertise. The record of the examination is submitted to the State Attorney's Office.

Experts from Forensic Science Centre „Ivan Vučetic“" are involved in crime scene investigation at the largest and most complex fires in industrial buildings. Their task is to determining the centre of the fire and cause of fire. 


\section{FIRE IN WOOD INDUSTRY}

\subsection{Information obtained at the scene}

A fire occurred in the company of wood industry on Saturday night about 01.30. First witness of fire was employee (night watchman) about 01.45, who noticed the break of power supply in the front circle of the company, and than he noticed smoke and flame in the briquette room. He tried to extinguish the fire using two fire extinguishers, when he failed, he called director of company who called fire fighters.

Fire brigade arrived on the fire scene at 02.10 (fire fighters from Zagreb City and volunteer fire fighters).

At 03.00 on the fire scene arrived the employers of Electra, who have turned off power supply.

About 04.00 fire was localized and stopped the danger that fire spread to surrounding buildings and houses.Company was working previous day up to 22.00 .

\subsection{Overview on the fire scene}

Wood industry employs about 90 workers, who are working on $30000 \mathrm{~m}^{2}$ of the production line for production of masiv floors (country floors) and timber construction. In the circle of the company are: family house with commercial rooms, building with an upgraded hall (production of masiv floor) along which there are 2 metal containers, another buildings (parquet production and production of briquettes), silos for sawdust, prefabricated hall (warehouse of country floors) and other buildings.

Large amount of final products (masiv floor), prefabricated warehous, electrical installation and equipment in more buildings, silos and most of the roof, structure and walls of buildings have been destroyed during the fire.

\subsection{Overview of electrical installation}

Review the house connecting cabinet, which is located in an open area within the circle of company. A review of the cabinet was found that the main fuses that protected the burned object were removed from their housing and there are located in the cabinet. The review determined that there are a fuses $(3 \times 250 \mathrm{~A})$, and by reviewing and testing it was found that the fuses were blown.

A review of electrical installation in the packing room, see Fig. 1, it was determinated that on the wall are five metal distribution cabinets.

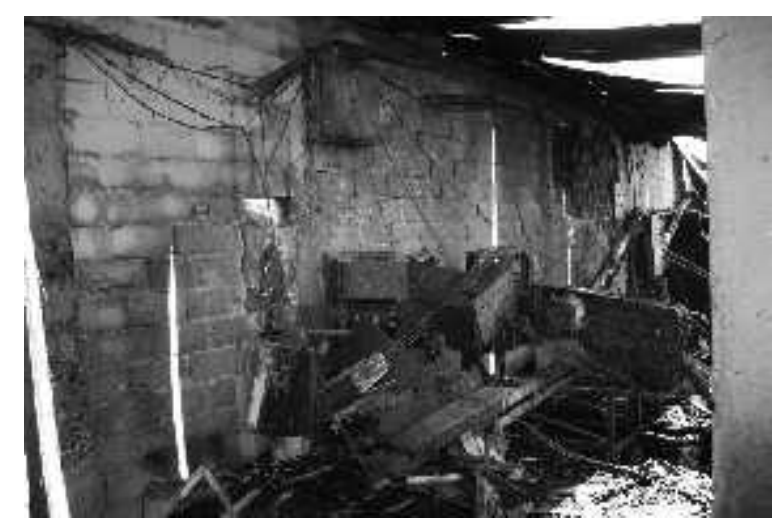

Fig. 1 Electrical installation in the burned room

By review of the first and second electric box, it was found that there was a complete thermal destruction of all combustible parts of the wire insulation and others, and protective elements that were in the boxes are dropped and are located in the fire debris. By examining the fuses were found in the fire debris that they were thermal completely destroyed so it is not possible to determine the technical characteristics and condition of protective elements. 
The review of second electric box, it was found that in one of the cables exiting through the top of the metal enclosure are traces of break and melting of copper wires, on the part of the cable which is located on the machine after the cable fell off the wall together with metal channel, see Fig. 2.

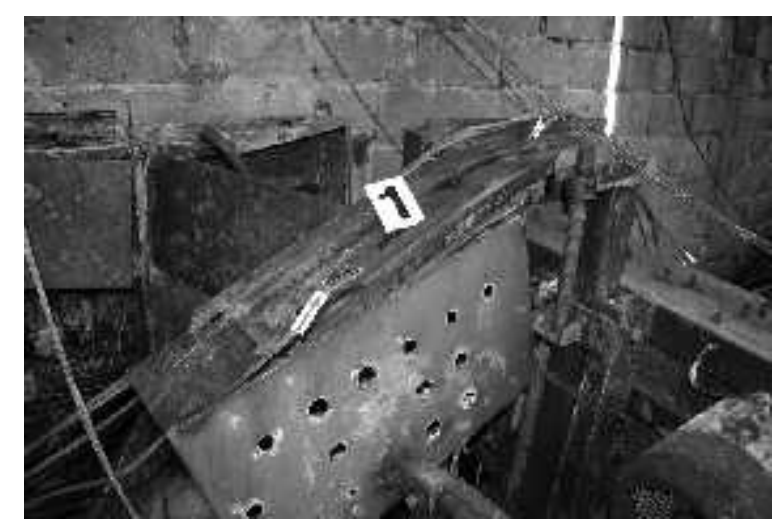

Fig. 2 Cable with traces of thermal damage and break

By review of the cable it was found that it is a four-wire cable that is thermally damaged in the form of complete burning insulation of cables and wires, and in one place there are traces of break and melting in one of the cable conductor. Detailed examination the place of a break on wires, there are the traces of melting in the form of balls, see Fig. 3.

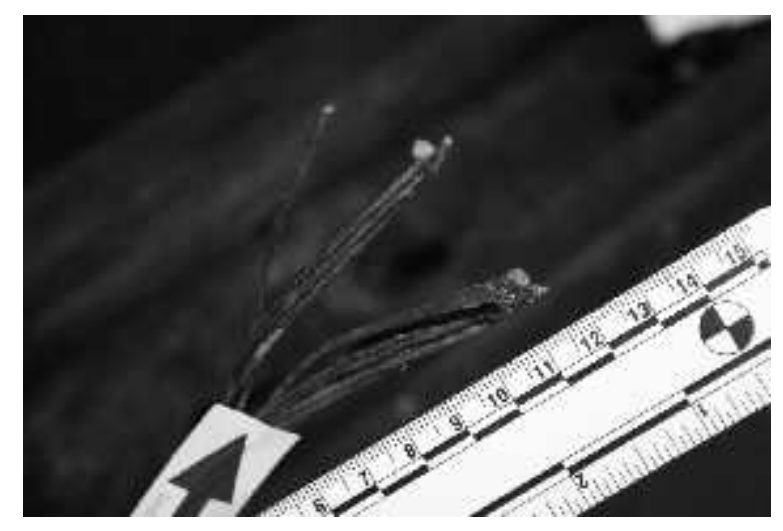

Fig. 3 Traces of melting wires at the place of break

The cable was laid in a metal channel which was located on the wall above the distribution cabinets. Part of electric cable with found traces was fixed with photograph and exempted by the crime technician.

By examining the electrical installation on the wall above the distribution cabinets, it was found that electric cables were placed in metal channels that were located on the wall above the distribution cabinets near the ceiling of the room, see Fig. 4.

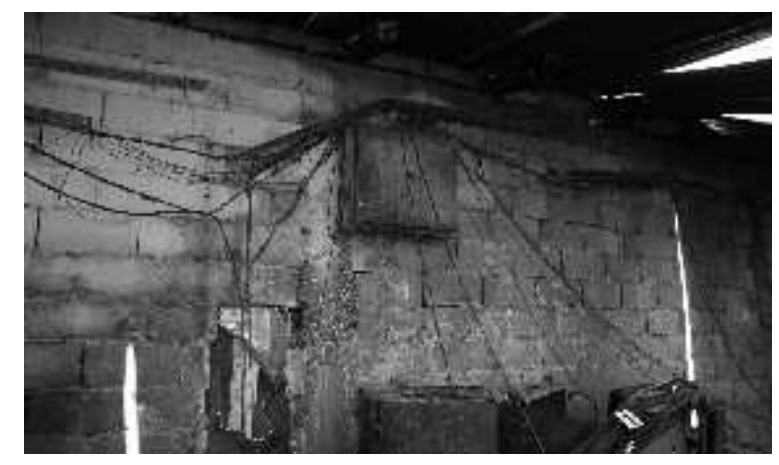

Fig. 4 Metal channels with cabels 
A review of the room, on the wall near to distribution cabinets, there are thermal damages on the wall of concrete blocks, and on the ceiling of the room are observed thermal damages in the form of complete combustion of the wooden part and falling tin parts of the roof into the room.

By examining the elektro-mechanical equipment in the room, there are intensively thermal damages.

It was further examined electrical installation and machines in the next room for briquette production (thermally damaged electrical cables, junction boxes and connection cables of machines and machines that were damaged in the fire), in order to determine the course of spread from the center of the fire to the place where fire was first observed.

\subsection{Review of materials expertise}

By reviewing submitted materials of expertise it has been found:

- Examination materials of expertise were found to be delivered two pieces of copper conductors multi-wire cross-section, who are cut off at one end. Cooper conductors are thermally damaged in the form of complete combustion of insulation, see Fig. 5.

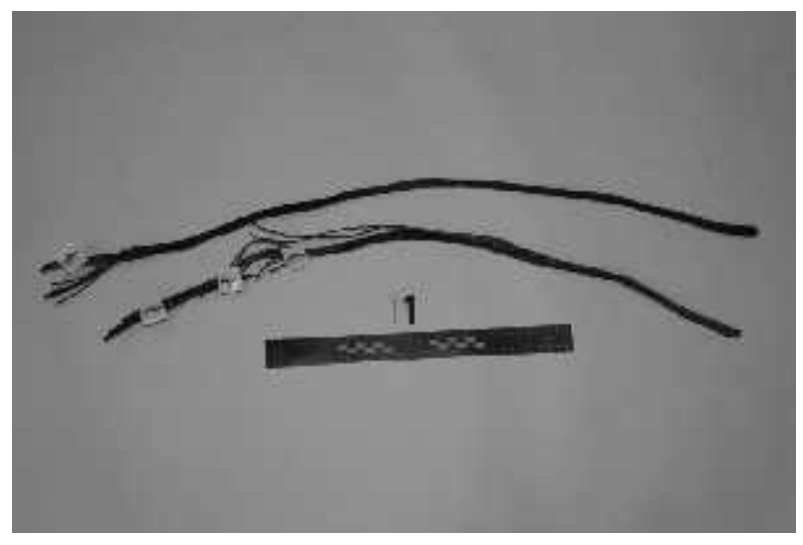

Fig. 5 Material of expertise

- Delivered one piece of copper conductor of 14 profile copper wires. At the end of the copper wires are traces of interruption, melting and mutual welding between the individual wires in the form of balls, see Fig. 6 .

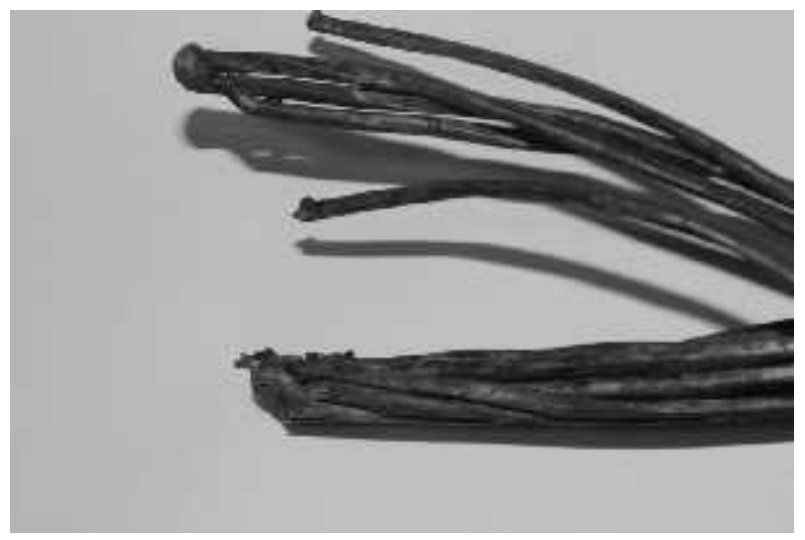

Fig. 6 Traces of the primary short circuit at the end of the conductor

- Delivered is another piece of cooper conductor consisting of 14 profile cooper wires. At the end of the copper wire are traces of interruption, melting and mutual melting between the individual wires, see Fig. 7. 


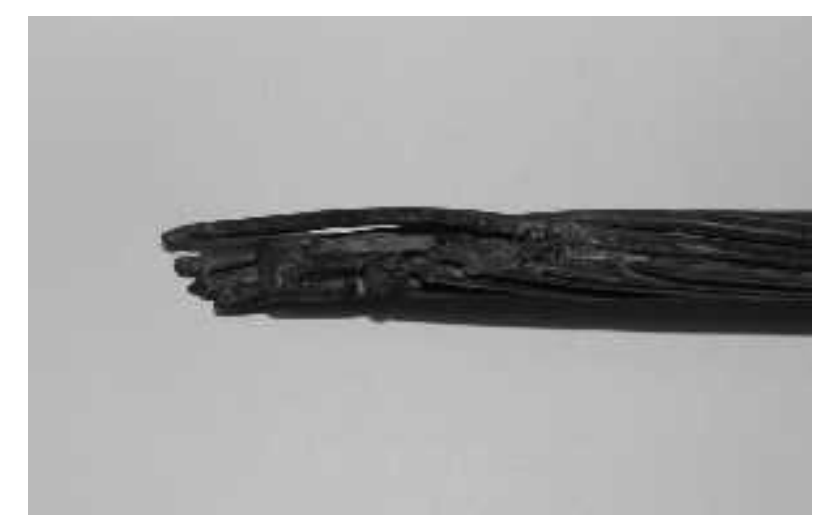

Fig. 7 Traces of the secondary short circuit at the end of the wire

- Similar traces of interruption and melting are located in several places of the wire, see Fig. 8.

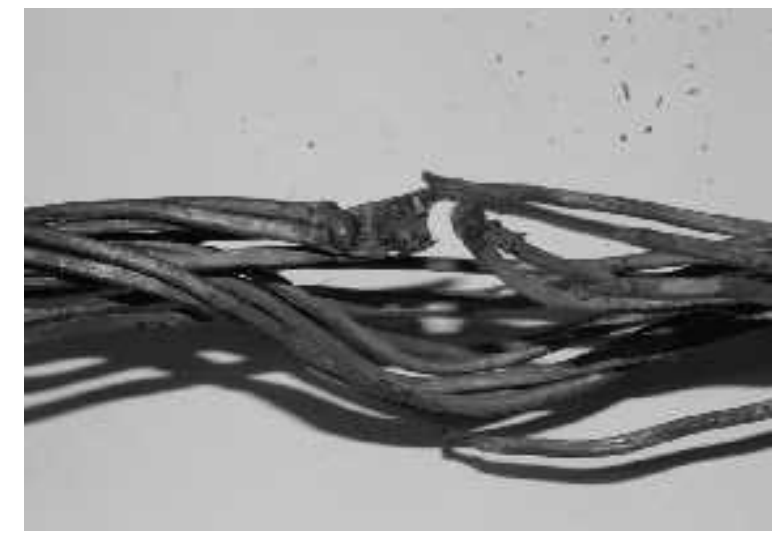

Fig. 8 Traces of the secondary short circuit at the part of the wire

\section{EXAME RESULTS AND ANALYSIS}

- A review of fire scene was determined that the largest thermal damages are in a room for packaging, where it came to a thermal damage of electrical installations, machinery, wood products, walls and roof construction of building, and in the next room for the production of briquettes.

- According to a statement by employees, it is noticed a outbreak of fire on Saturday abaut 01.30 in the room for production of briquettes, in part of the room where is a wall with an opening to the neighboring packing room.

- A review of electrical installation in the packing room can be found on the four-wire cable, which was located in the channel on the wall of the room, characteristic traces of break and melting on a single copper wire.

- A review of the room, there were observed the largest thermal damages on the walls of concrete blocks, and on the ceiling of the room were observed thermal damages in the form of a complete combustion of the wooden part of the roof and falling tin lid into the room.

- A review of the house connecting cabinet, it was found three main fuses that protected electrical installation of fire-affected building, burne out.

- A review of material of expertise, it was found that in a wire break place are traces of melting wire in the form of balls, which indicating that there was a short circuit which could ignite the first insulation of conductor, and then a wooden structure of the roof of the facility which is located above the channel in which laid the cable installation.

- Traces of melting on the other parts of the conductor are the result of secondary short-circuit, resulting in the electrical installation as a result of the previously created fire. 


\section{CONCLUSIONS}

On the basis of the reviews of fire scene and examination and test of material of expertise, was concluded that the cause of fire is technical malfunction on the power cable which powered electrical installation in a room for packaging. First come to the ignition of the insulation of the cable, and fire is further expanded on the wooden roof construction and fuel materials in the room. Through the roof structure fire is expanded to the adjacent room for briquetting, where it was spotted by the nightguard.

Short circuit, which has led to the fire, was created due to the damage of the insulation of conductor, which might be due to mechanical damage during the assembly, ageing and the breakdown of the insulation, the overload or the other.

In addition to the combustible materials in the wood industry are in the raw material and products, an important factor that can lead to the occurrence and ease of spread of fire is a building construction object in which is situated the production equipment. In the specific case of the emergence and development of fire is favorable to the performance of the electrical installation under the ceiling and the roof structure of the fuel materials, and a large amount of combustible materials in the form of wood dust and sawdust and finished products.

\section{REFERENCES}

Forensic Science Centre „Ivan Vučetić“, 2001.-2014.: Records of forensic analysis.

Forensic Science Centre „Ivan Vučetić“, 2013.: Inspection and testing of electrical installation and equipments in buildings and the determination of the origin and cause of the fire, work instructions.

Forensic Science Centre „Ivan Vučetic““, 2013.: The form for the inspection of electrical installation and devices for fire in buildings. 